\title{
Identification and agreement of first turn point by mathematical analysis applied to heart rate, carbon dioxide output and electromyography
}

\author{
Antonio R. Zamunér ${ }^{1}$, Aparecida M. Catai ${ }^{1}$, Luiz E. B. Martins ${ }^{2}$, \\ Daniel I. Sakabe ${ }^{1}$, Ester Da Silva ${ }^{1}$
}

\begin{abstract}
Background: The second heart rate (HR) turn point has been extensively studied, however there are few studies determining the first HR turn point. Also, the use of mathematical and statistical models for determining changes in dynamic characteristics of physiological variables during an incremental cardiopulmonary test has been suggested. Objectives: To determine the first turn point by analysis of HR, surface electromyography (sEMG), and carbon dioxide output $\left(\dot{\mathrm{VCO}}_{2}\right)$ using two mathematical models and to compare the results to those of the visual method. Method: Ten sedentary middle-aged men $(53.9 \pm 3.2$ years old) were submitted to cardiopulmonary exercise testing on an electromagnetic cycle ergometer until exhaustion. Ventilatory variables, HR, and sEMG of the vastus lateralis were obtained in real time. Three methods were used to determine the first turn point: 1) visual analysis based on loss of parallelism between $\dot{\mathrm{VCO}}_{2}$ and oxygen uptake $\left.\left(\mathrm{VO}_{2}\right) ; 2\right)$ the linear-linear model, based on fitting the curves to the set of $\mathrm{VCO}_{2}$ data (Lin-LinVCO ${ }_{2}$; 3 ) a bi-segmental linear regression of Hinkley's algorithm applied to HR (HMM-HR), $\dot{\mathrm{VCO}}_{2}\left(\mathrm{HMM}-\dot{\mathrm{VCO}}_{2}\right)$, and sEMG data (HMM-RMS). Results: There were no differences between workload, HR, and ventilatory variable values at the first ventilatory turn point as determined by the five studied parameters $(\mathrm{p}>0.05)$. The Bland-Altman plot showed an even distribution of the visual analysis method with Lin-LinVCO, HMM-HR, HMM$\mathrm{VCO}_{2}$, and HMM-RMS. Conclusion: The proposed mathematical models were effective in determining the first turn point since they detected the linear pattern change and the deflection point of $\mathrm{VCO}_{2}$, HR responses, and sEMG.
\end{abstract}

Keywords: physical therapy; anaerobic threshold; exercise test; mathematical models.

\section{HOW TO CITE THIS ARTICLE}

Zamunér AR, Catai AM, Martins LEB, Sakabe DI, Da Silva E. Identification and agreement of first turn point by mathematical analysis applied to heart rate, carbon dioxide output and electromyography. Braz J Phys Ther. 2013 Nov-Dec; 17(6):614-622. http:// dx.doi.org/10.1590/S1413-35552012005000129

\section{Introduction}

Physical exercise requires the interaction of different physiological mechanisms that enable the cardiorespiratory system to support the increased energy demands of contracting muscles. The system's ability to accomplish this task is linked with its ability to maintain homeostasis and is a measure of functional capacity. Therefore, measuring the responses of interactive systems (e.g. cardiorespiratory and muscular systems) is extremely important in studies about physical exercise ${ }^{1}$.

A number of studies have considered the concept of a three-phase model due to the fact that, with an intensity increment, three phases of energy supply and two points of intersection are observed ${ }^{2}$. The first phase of energy supply involves greater oxygen extraction by tissues, resulting in a lower fraction of oxygen in expired air. More carbon dioxide is also produced and expired. Therefore, a linear increase in oxygen uptake $\left(\dot{\mathrm{VO}}_{2}\right)$, carbon dioxide output $\left(\dot{\mathrm{V}} \mathrm{CO}_{2}\right)$ and pulmonary ventilation (VE) is found with no significant increase in the blood lactate concentration. In phase II, the intensity is above the first intersection point. The rate of lactate production is greater than the metabolic capacity of the muscle cells, which results in an increase in blood lactate concentration. Nevertheless, the oxidative capacity of the entire system is great enough to cope with the incoming lactate. Phase III is above the second intersection point, where the rate of muscle lactate production exceeds the system's rate of elimination. Increases in carbon dioxide production and ventilation become nonlinear, and hyperventilation cannot adequately compensate for the increase in $\mathrm{H}+{ }^{2,3}$.

${ }^{1}$ Physical Exercise Research Center (NUPEF), Physical Therapy Department, Universidade Federal de São Carlos (UFSCar), São Carlos, SP, Brazil ${ }^{2}$ Exercise Physiology Laboratory, Physical Education College, Universidade Estadual de Campinas (UNICAMP), Campinas, SP, Brazil Received: 05/08/2013 Revised: 05/16/2013 Accepted: 06/07/2013 
Visual analysis of the disproportionate increase in carbon dioxide output $\left(\dot{\mathrm{VCO}}_{2}\right)$ in relation to the linear increase in oxygen uptake $\left(\mathrm{VO}_{2}\right)$ is a noninvasive method that has been widely used to detect the first turn point, i.e. the exercise level at which the production of energy by aerobic metabolism is supplemented by anaerobic metabolism ${ }^{1,4}$. This type of analysis is considered the gold standard by some researchers ${ }^{5-8}$. However, besides its high cost, this methodology has also been considered controversial due to the subjectivity in determining the first turn point, poor reproducibility, and poor interobserver/interalgorithm agreement ${ }^{9}$. Therefore, the use of mathematical and statistical models has been suggested, primarily due to their low cost, to quantify and objectively determine the intensity at which loss of linearity or change in the dynamic characteristics of physiological variables occurs during an incremental cardiopulmonary test.

Conconi et al. ${ }^{10}$, in an incremental field test for runners, proposed a noninvasive method for determining the anaerobic threshold that is equivalent to the second lactate turn point: the deflection point of HR response (second HR turn point). Hofmann et al. ${ }^{11}$ investigated the second HR turn point with computeraided linear regression break point analysis of the power output/HR relationship. They found no significant differences in any measured variables regarding the second lactate turn point. Still other studies have demonstrated that, although a second HR turn point cannot always be detected because HR behavior varies from individual to individual during tests (due to its association with factors such as differences in $\beta 1$ adrenoreceptor sensitivity), it can be used as a parameter for prescribing exercise intensity ${ }^{12,13}$.

Although HRPT ${ }_{2}$ has been extensively studied in the literature, there are few studies determining the first heart rate (HR) turn point. Crescêncio et al. ${ }^{7}$ and Higa et al..$^{8}$ determined the first HR turn point with a linear-linear model and a Hinkley bi-segmental linear regression model, respectively. Both methods were effective and did not present significant differences compared to the gold standard adopted in both studies (i.e. visual analysis of a disproportionate increase in $\stackrel{\mathrm{VCO}}{2}$ in relation to the linear increase in $\mathbf{\mathrm { VO }}_{2}$ ).

Moreover, in recent decades it has been demonstrated that determining the moment when muscular fatigue begins is important for providing a better prescription of exercise for those who need to improve functional aerobic capacity. To this end, some studies ${ }^{14-16}$ have suggested using surface electromyography (sEMG) to determine the first turn point for the root mean square (RMS) of the myoelectric signal. This method is based on the principle that beginning at the first turn point, there is a higher blood lactate production rate than removal rate, which causes a metabolic imbalance that leads to additional motor unit recruitment and an increased depolarization frequency in active muscles ${ }^{15,17}$. However, computational models or algorithms that enable automated detection of the muscular fatigue threshold are still underexplored ${ }^{18}$.

Based on these considerations, the aims of this study were, first, to determine the first turn point for HR using a mathematical model and then to compare this result with mathematically determined first turn point values for the RMS index of sEMG and $\mathbf{V C O}_{2}$ as well as with the visual method.

\section{Method}

\section{Experimental approach to the problem}

Three methods were employed to determine the first turn point during cardiopulmonary exercise testing. In the first method, three properly trained observers evaluated the first $\dot{\mathrm{VCO}}_{2}$ turn point with visual analysis by identifying a disproportionate increase in ventilatory and metabolic variables. The criterion adopted was a loss of parallelism between $\dot{\mathrm{V}}_{2}$ and $\dot{\bullet}_{\mathrm{VO}}{ }_{2}^{7,8}$. The first $\dot{\mathrm{V}}_{2} \mathrm{CO}_{2}$ turn point identified by the visual method will be designated as the standard turn point model (STPM) to avoid any nomenclature confusion. This point was expressed in terms of workload, $\dot{\mathrm{VO}}_{2}$ and $\mathrm{HR}$ values by the calculated mean of the results from the three analyzers. The second method involved a semi-automatic technique based on the use of a linear-linear model for $\dot{\mathrm{VCO}}_{2}$ (Lin-Lin $\mathrm{VCO}_{2}$ ) response in relation to time ${ }^{6}$. This model was applied following Soler et al. ${ }^{6}$ and Crescêncio et al. ${ }^{7}$ based on the fitting of curves to the set of $\dot{V C O}_{2}$ data (80 to 160 points). The data were divided into 2 subsets by an algorithm developed in the S-plus statistical package: the $\mathrm{VCO}_{2}$ values at the beginning of ramp elevation until an intermediate point corresponding to $\mathrm{S} 1$, while the $\dot{\mathrm{VCO}}_{2}$ values from the intermediate point until the final third of ramp elevation corresponded to $\mathrm{S} 2$. The $\mathrm{S} 1$ and $\mathrm{S} 2$ values corresponded to the fitting of two lines and, in a subsequent stage, the residual sum of squares (RSS) of the tested model was calculated. Figure 1 illustrates the RSS for fitting the Lin-Lin model. The point chosen as the first $\dot{V C O}_{2}$ turn point corresponded to the lowest RSS value or to the median value in cases of a plateau (5 to 15 points) instead of a single RSS minimum point. The third approach involved a 


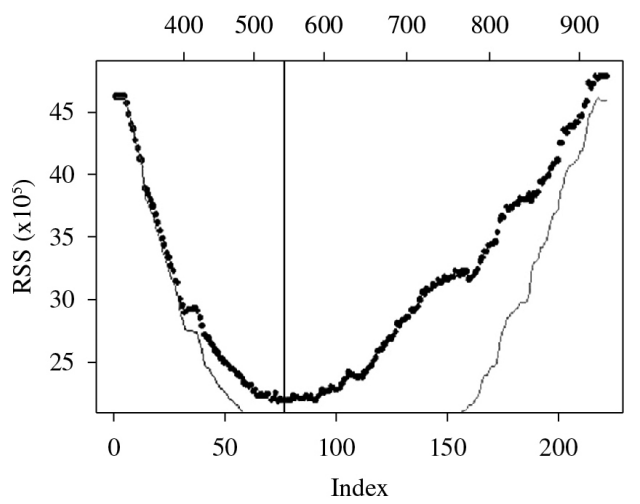

Figure 1. Illustration of the residual sum of squares (RSS) of the linear-linear mathematical model applied to the carbon dioxide output data from one of the subjects studied. The vertical straight line identifies the moment of ventilatory anaerobic threshold (VAT) detected by this method.
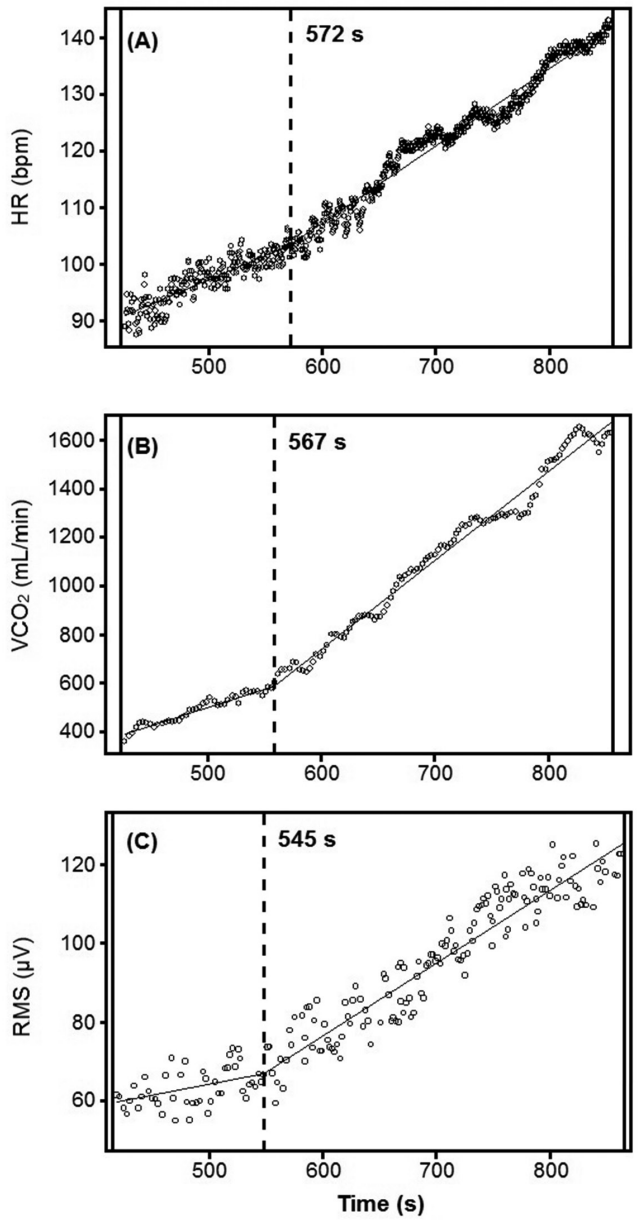

Figure 2. Hinkley's mathematical model fitted to carbon dioxide output $\left(\mathrm{VCO}_{2}\right)$ obtained on a breath-by-breath basis (A), to heart rate data collected on a beat-to-beat basis (B), and to the RMS of surface electromyography $(\mathrm{C})$ of one of the study volunteers. The vertical dotted line determines the change point in each variable's response. The vertical solid lines represent the lower and the upper limits of the region of interest for the mathematical determination of turn points. The time shown at the top of each graph was considered the first turn point time detected by this method. bisegmental linear regression model ${ }^{19}$ applied with an algorithm developed in the S-plus statistical package ${ }^{6}$. This model determined a series of data change points with the maximum likelihood method and was fitted to each study participant, to beat-to-beat collected HR data (HMM-HR), and to the RMS of sEMG (HMM-RMS; Figure 2).

\section{Subjects}

In this cross-sectional study, 10 sedentary middleaged men $(53.9 \pm 3.2$ years old, $72.5 \pm 8.8 \mathrm{~kg}, 166 \pm 5$ $\mathrm{cm}, 26 \pm 2.6 \mathrm{~kg} \cdot \mathrm{m}^{-2}$ ) were investigated. Ethical approval was obtained from the Research Ethics Committee of Universidade Federal de São Carlos (UFSCar), São Carlos, SP, Brazil (protocol number: 065/2002), and all participants gave written informed consent. All subjects were in good health and were not on any medication.

Participants underwent a physical evaluation (muscles and joints), resting HR and blood pressure measurement, heart and lung auscultation, a standard electrocardiogram (ECG), laboratory screening tests (glucose, triglycerides, total cholesterol and fractions, type 1 urinalysis), and a continuous dynamic cardiopulmonary exercise test on a cycle ergometer. Clinical examination and laboratory tests showed no evidence of any cardiorespiratory abnormalities in the group.

\section{Procedures}

The included subjects also underwent maximal cardiopulmonary exercise testing. All experiments were carried out between 2 and 4 p.m. to avoid response variation due to circadian changes. The room temperature and relative air humidity of the testing laboratory were kept at $23^{\circ} \mathrm{C}$ and between $40 \%$ and $60 \%$, respectively. The subjects were acquainted with the experimental protocol and instructed to abstain from stimulants (coffee, tea, soft drinks) and alcoholic beverages, avoid exhausting physical activity in the $24 \mathrm{~h}$ prior to the exam, and to have a light meal at least $2 \mathrm{~h}$ before testing.

Cardiopulmonary exercise testing was performed on a cycle ergometer with electromagnetic braking (Quinton Corival 400, Seattle, WA, USA) and seat adjusted to allow approximately 5 to 10 degrees of knee flexion. The protocol consisted of 1 minute pretesting while seated in a resting position on the cycle ergometer followed by a 4 minute warm-up period at $4 \mathrm{~W}$. The workload was then increased continuously by $16.71 \pm 1.30 \mathrm{~W} / \mathrm{min}$ until physical exhaustion, i.e. the moment at which the subject could no longer maintain $60 \mathrm{rpm}$ or the occurrence of a limiting 
symptom or respiratory fatigue. Workload increments were determined for each subject according to the formula proposed by Wasserman et al. ${ }^{1}$ (Workload increase $(W)=[($ height - age $) \times 20]-[150+(6 \mathrm{x}$ body mass)]/100.

During the test, ECG and HR were recorded beat-to-beat with a one-channel heart monitor (MINISCOPE II Instramed, Porto Alegre, RS, Brazil) and processed with a Lab PC + analog-todigital converter (National Instruments Co., Austin, TX, USA), which acted as an interface between the heart monitor and a computer. The ECG signal was recorded in real time after analog-to-digital conversion at a sampling rate of $500 \mathrm{~Hz}^{20}$.

For sEMG data acquisition, a 16-channel surface electromyography machine (Lynx Tecnologia Eletrônica Ltda, São Paulo, SP, Brazil) and signal acquisition software (AqDados5) were used. The machine features 16 independent-channel analog signal conditioning modules (MCS 1000V2) and an analog/digital transformer card (CAD 12/32, 12-bit resolution with amplifier), which interfaces with a desktop computer. sEMG signals were digitized at a sampling frequency of $1000 \mathrm{~Hz}$ with a frequency band ranging from 20 to $500 \mathrm{~Hz}$.

Bipolar (2 cm center-to-center distance) NORAXON $(\mathrm{Ag} / \mathrm{AgCl})$ dual surface electrodes were placed over the vastus lateralis of the right leg, following Basmajian and De Luca ${ }^{21}$, at approximately the midpoint between the head of the greater trochanter and the lateral condyle of the femur ${ }^{22}$. The RMS of sEMG of each muscle contraction was calculated throughout the protocol.

Ventilatory and metabolic variables were collected and stored on a breath-by-breath basis using a metabolic analyzer (CPXD, Medical Graphics, St. Paul, MN, USA). The system consisted of a desktop computer with a Pentium III $1100 \mathrm{MHz}$ processor and an analog/digital transformer card set at a sampling frequency of 250 values per second (MedGraphics Service Manual); Breeze Suite 5.3.007 software was used to process and print the ventilatory and metabolic data in different formats.

For all methods of determining the first turn point, a ramp interval was selected in which ventilatory variables began to respond to workload increases until the respiratory compensation point (RCP) was reached or, in cases where the RCP could not be observed, until the end of the exercise. This procedure was adopted because determining the first turn point is based on response changes by ventilatory variables due to the imbalance between the production and elimination of lactic acid in muscle tissues during exercise and not on occasional changes in these responses resulting from other metabolic mechanisms that occur later, i.e. in the final third of the ramp workload $^{1}$. Furthermore, for proper adjustment, the mathematical models used in the present study require that the responses of the chosen variables to the respective adjustments involve only one inclination change between the lines.

\section{Statistical analysis}

The data are presented as mean \pm standard deviation (SD). All data showed a normal distribution in the Shapiro-Wilk test. One-way ANOVA was applied, followed by Tukey's post-hoc test for multiple comparisons. Pearson's correlation test was used to verify the relationship between data. Bland and Altman $^{23}$ plots were used to analyze the limits of agreement between the STPM and Lin-Lin ${ }^{\circ} \mathrm{CO}_{2}$, HMM-HR, HMM- $\dot{\mathrm{V}}_{2}$, and HMM-RMS. The significance level was set at 5\%. The data were analyzed in SPSS version 17.0. The sample size was determined using $G^{*}$ Power 3.1.3 for Windows based on a pilot study comparing values for $\stackrel{\bullet}{\mathrm{VO}}_{2}(\mathrm{ml}$. $\left.\mathrm{kg} \cdot \mathrm{min}^{-1}\right)$ at the ventilatory anaerobic threshold in the five proposed parameters: graphic visual analysis, Lin-Lin $\mathrm{VCO}_{2}, \mathrm{MMH}-\dot{\mathrm{VCO}}_{2}, \mathrm{MMH}-\mathrm{HR}$, and MMHRMS. For an alpha error of 0.05 and test power of $80 \%$, the recommended number of participants was 9 .

\section{Results}

In the five studied parameters, there were no significant differences between workload, HR and the values of each ventilatory variable at the first turn point $(p>0.05)$. The values of these variables are expressed in Table 1 as mean \pm SD.

Significant correlations were observed between power, $\dot{\mathrm{VO}}_{2}$ and HR, and the STPM in the different mathematical models used (Table 2). Significant correlations were also found between the first HR turn point and the other methods used in this study (Table 2). The Bland-Altman plot shows an even distribution of the STPM with Lin-LinVCO ${ }_{2}$, HMM$\dot{\mathrm{VCO}}_{2}, \mathrm{HMM}-\mathrm{RMS}$, and HMM-HR without deviation from the mean value of the ventilatory anaerobic threshold (Figure 3A-D). This was also observed in Bland-Altman plots for HMM-HR distribution in the other methods used (Figure 3E-G). 
Table 1. The values at the first turn point determined by the standard turn point method (STPM), Lin-LinVCO ${ }_{2}$ model, $\mathrm{HMM}_{\mathrm{V}} \mathbf{\mathrm { V }}^{\mathrm{V}} \mathrm{O}_{2}$, HMM-RMS, and HMM-HR. The region of interest for analysis comprises the beginning of the ventilatory responses to increasing load until the point of respiratory compensation, or until the end of the exercise. Data are mean \pm SD.

\begin{tabular}{|c|c|c|c|c|c|c|}
\hline \multirow[b]{2}{*}{ Variables } & \multirow{2}{*}{$\begin{array}{c}\text { Exercise } \\
\text { peak }\end{array}$} & \multicolumn{5}{|c|}{ First Turn Point Determination Methods } \\
\hline & & STPM & Lin-Lin $\dot{\mathrm{VCO}}_{2}$ & HMM- ${\stackrel{\bullet}{V} \mathrm{CO}_{2}}_{2}$ & HMM-RMS & HMM-HR \\
\hline Workload (Watts) & $142.6 \pm 17.0$ & $65.1 \pm 11.1$ & $64.3 \pm 12.5$ & $62.5 \pm 10.8$ & $68.9 \pm 15.1$ & $65.0 \pm 11.9$ \\
\hline HR (bpm) & $148.3 \pm 15.2$ & $97.4 \pm 12.7$ & $97.8 \pm 13.1$ & $96.9 \pm 11.3$ & $98.9 \pm 10.6$ & $95.4 \pm 11.5$ \\
\hline$\stackrel{\bullet}{\mathrm{VO}_{2}}\left(\mathrm{mlO}_{2} \cdot \mathrm{kg}^{-1} \cdot \mathrm{min}^{-1}\right)$ & $21.3 \pm 1.4$ & $10.9 \pm 1.9$ & $10.8 \pm 1.8$ & $10.6 \pm 1.5$ & $11.5 \pm 1.7$ & $11.0 \pm 1.8$ \\
\hline$\dot{\mathrm{VO}}_{2}(\mathrm{~L} / \mathrm{min})$ & $1.5 \pm 0.3$ & $0.8 \pm 0.1$ & $0.8 \pm 0.1$ & $0.8 \pm 0.1$ & $0.8 \pm 0.2$ & $0.8 \pm 0.1$ \\
\hline$\dot{\mathrm{VCO}}_{2}(\mathrm{~L} / \mathrm{min})$ & $1.9 \pm 0.3$ & $0.8 \pm 0.1$ & $0.8 \pm 0.1$ & $0.7 \pm 0.1$ & $0.8 \pm 0.2$ & $0.8 \pm 0.1$ \\
\hline$\stackrel{\bullet}{\mathrm{VE}}(\mathrm{L} / \mathrm{min})$ & $64.5 \pm 14.0$ & $24.8 \pm 4.9$ & $24.5 \pm 4.9$ & $23.9 \pm 4.4$ & $26.2 \pm 5.3$ & $25.1 \pm 4.9$ \\
\hline RER & $1.2 \pm 0.1$ & $0.98 \pm 0.03$ & $0.98 \pm 0.04$ & $0.98 \pm 0.04$ & $0.99 \pm 0.05$ & $0.97 \pm 0.04$ \\
\hline
\end{tabular}

Lin-Lin $\dot{\mathrm{VCO}_{2}}=$ Linear linear bi-segmental model fitted to dioxide carbon output, $\mathrm{HMM}-\dot{\mathrm{VCO}}_{2}=$ Hinkley's mathematical model fitted to dioxide carbon output, HMM-RMS = Hinkley's mathematical model fitted to RMS index of myoelectric signal, HMM-HR = Hinkley's mathematical model fitted to heart rate, $\mathrm{VO}_{2}=$ oxygen uptake, $\mathrm{HR}=$ heart rate, $\mathrm{VE}=$ ventilation, $\mathrm{RER}=$ respiratory exchange ratio.

Table 2. Pearson's Correlation Coefficients considering the standard turn point method (STPM) and the first HR turn point as dependent variables.

\begin{tabular}{|c|c|c|c|}
\hline STPM & Mathematical Models & $\mathbf{r}$ & $p=$ \\
\hline \multirow[t]{3}{*}{ Workload (Watts) } & Lin-Lin $\dot{V}^{-} \mathrm{CO}_{2}$ & 0.90 & 0.0004 \\
\hline & $\mathrm{HMM}-\dot{\mathrm{V} C O}{ }_{2}$ & 0.88 & 0.0007 \\
\hline & HMM-RMS & 0.70 & 0.03 \\
\hline \multirow[t]{3}{*}{$\dot{\mathrm{VO}}_{2}\left(\mathrm{mlO}_{2} \mathrm{~kg}^{-1} \cdot \mathrm{min}^{-1}\right)$} & Lin-LinVं $\mathrm{CO}_{2}$ & 0.90 & 0.0003 \\
\hline & $\mathrm{HMM}-\dot{\mathrm{V} C O}{ }_{2}$ & 0.92 & 0.0001 \\
\hline & HMM-RMS & 0.72 & 0.02 \\
\hline \multirow[t]{3}{*}{ HR (bpm) } & Lin-Lin $\dot{V C O}_{2}$ & 0.94 & $<0.0001$ \\
\hline & $\mathrm{HMM}-\dot{\mathrm{VCO}}_{2}$ & 0.95 & $<0.0001$ \\
\hline & HMM-RMS & 0.97 & $<0.0001$ \\
\hline HMM-HR & First turn point methods & $\mathbf{r}$ & $\mathbf{p}=$ \\
\hline \multirow[t]{4}{*}{ Workload (Watts) } & STPM & 0.90 & 0.0005 \\
\hline & Lin-Lin $\dot{V}^{-} \mathrm{CO}_{2}$ & 0.81 & 0.004 \\
\hline & $\mathrm{HMM}-\dot{\mathrm{VCO}}_{2}$ & 0.74 & 0.01 \\
\hline & HMM-RMS & 0.70 & 0.02 \\
\hline \multirow[t]{4}{*}{$\dot{\mathrm{VO}}_{2}\left(\mathrm{mlO}_{2} \mathrm{~kg}^{-1} \cdot \mathrm{min}^{-1}\right)$} & STPM & 0.93 & 0.0001 \\
\hline & Lin-Lin $\dot{V C O}_{2}$ & 0.86 & 0.001 \\
\hline & $\mathrm{HMM}-\dot{\mathrm{V} C O}{ }_{2}$ & 0.80 & 0.005 \\
\hline & HMM-RMS & 0.77 & 0.009 \\
\hline \multirow[t]{4}{*}{ HR (bpm) } & STPM & 0.94 & $<0.0001$ \\
\hline & Lin-LinVंCO & 0.88 & 0.0007 \\
\hline & $\mathrm{HMM}-\dot{\mathrm{VCO}}_{2}$ & 0.90 & 0.0004 \\
\hline & HMM-RMS & 0.77 & 0.009 \\
\hline
\end{tabular}

$\dot{\mathrm{VO}}_{2}=$ oxygen uptake, $\mathrm{HR}=$ heart rate, $\mathrm{Lin}-\mathrm{LinVCO}_{2}=$ Linear linear bi-segmental model fitted to dioxide carbon output, $\mathrm{HMM}_{\mathrm{V}} \dot{\mathrm{VCO}}_{2}$ = Hinkley's mathematical model fitted to dioxide carbon output, HMM-HR = Hinkley's mathematical model fitted to heart rate, HMMRMS = Hinkley's mathematical model fitted to RMS index of myoelectric signal. 

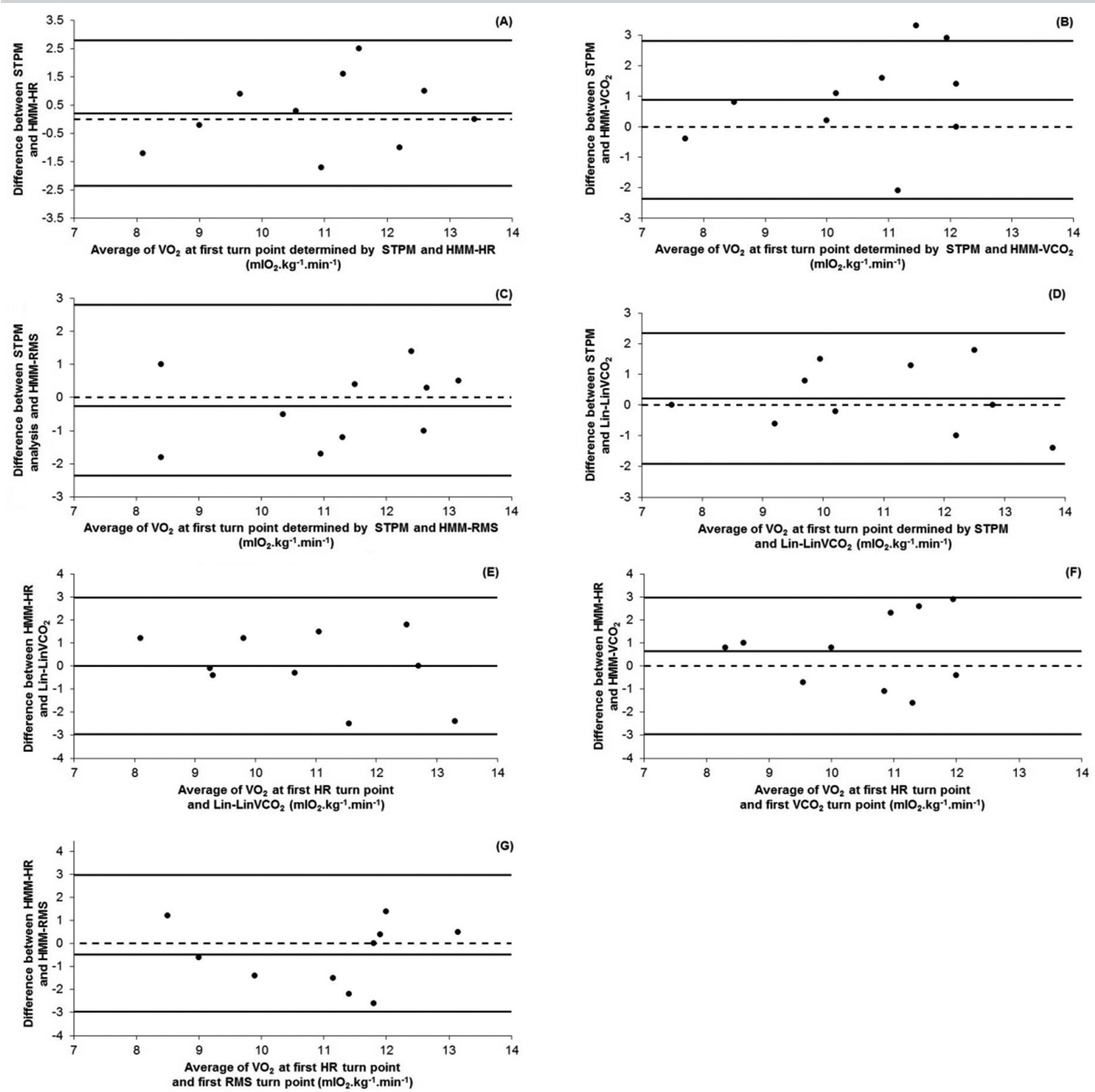

Figure 3. Bland-Altman plots showing differences between first turn point determined by the standard turn point method (STPM) versus: A) the Hinkley mathematical model fitted to heart rate (HMM-HR), B) carbon dioxide output $\left.\left(\mathrm{HMM}-\dot{V}_{2} \mathrm{CO}_{2}\right), \mathrm{C}\right)$ the RMS of surface electromyography (HMM-RMS), D) the linear-linear model based on fitting the curves to the set of carbon dioxide output data (Lin-

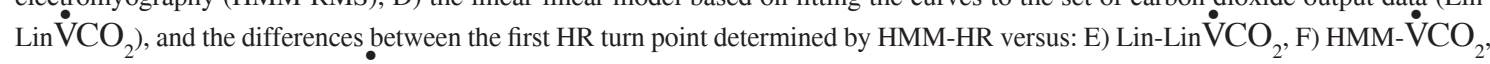
and G) HMM-RMS. Values in $\dot{\mathrm{VO}}_{2}\left(\mathrm{mlO}_{2} \mathrm{~kg}^{-1} \mathrm{~min}^{-1}\right)$.

\section{Discussion}

The main finding of our study was the good agreement between the first HR turn point determined by the bisegmental linear regression of Hinkley's algorithm and the STPM. Moreover, the good agreement and strong correlation found between the mathematical models used to determine the first turn point regardless of the outcome variable (i.e. $\mathrm{HR}, \mathrm{VCO}_{2}$, and sEMG) and the standard turn point method should also be mentioned.

The physical exercise level at which the production of energy by aerobic metabolism is supplemented by anaerobic metabolism has been intensely studied in different aspects, both physiological and methodological. The mechanisms responsible for these changes in the dynamics of the physiological variables during incremental exercise, as well as the different techniques for detecting these changes are objects of interest for researchers in the field of exercise physiology.

Scientists of different fields have always demonstrated interest in characterizing real phenomena, whether physical, chemical or biological, by means of mathematical tools ${ }^{4,7,8}$. In the field of 
exercise physiology, the use of mathematical models is an attempt to represent certain types of dynamic behavior of biological systems and their interactions during physical exercise practice ${ }^{24}$.

According to Rosic et al. ${ }^{25}$, the application of proper mathematical functions can contribute to a qualitative improvement in the analysis of dynamic physiological variable responses to stimuli such as the incremental stress test, thus making the identification of changes in the steady state more objective. In the present study, Lin-Lin mathematical models were applied to $\dot{\mathrm{VCO}}_{2}$ data and Hinkley's algorithm was applied to $\mathrm{HR}, \mathrm{VCO}_{2}$ and the RMS of sEMG signals.

A significant correlation was observed between Lin-LinVCO ${ }_{2}$ and STPM with respect to workload values, $\mathrm{HR}$, and $\dot{\mathrm{VO}}_{2}$ at the first turn point. These data corroborate the findings of Crescêncio et al. ${ }^{7}$, who found high correlation coefficients between workload and $\dot{\mathrm{VO}}_{2}$ at the first turn point, indicating that the performance of Lin-Lin $\mathrm{VCO}_{2}$ was satisfactory compared to STPM. However, Crescêncio et al. ${ }^{7}$ reported a systematic error in the Lin-LinVCO ${ }_{2}$ model for determining the first turn point of ventilatory variables. They found that, compared to STPM, the mathematical model has a tendency to underestimate workload and $\dot{\mathrm{VO}}_{2}$, which was not observed in the present study.

This difference could be related to the characteristics of the study participants, since Crescêncio et al. ${ }^{7}$ evaluated active and sedentary 18 to 55 year olds, whereas a more homogenous sample of sedentary middle-aged men was used in the present study. Nevertheless, the results obtained in both studies, especially the strong correlation and good agreement in the Bland-Altman analysis, suggest that the use of Lin-LinVCO ${ }_{2}$ is a promising quantification tool for objectively determining the first ${ }_{\mathrm{V}} \mathrm{CO}_{2}$ turn point.

Even though ventilatory and metabolic variable analysis is a standard reference for determining the first turn point, the use of ergospirometry equipment is generally restricted to research laboratories and is limited by high acquisition and maintenance costs and by the complex handling involved. Therefore, simpler and lower-cost resources, such as the data acquisition of HR, have been suggested as evaluation methods of functional capacity in individuals undergoing daily physical training programs in outpatient clinics, medical clinics and gyms, since these methods can properly represent the responses of their respective systems during physical exercise. For this reason, Hinkley's ${ }^{19}$ algorithm was used to determine the first HR turn point in the present study. Hinkley's ${ }^{19}$ mathematical model is based on the maximum likelihood method for detecting a change point in the behavior pattern of a series of data collected during an incremental dynamic exercise test.

The changes in response patterns of cardiorespiratory variables have been well established in the literature ${ }^{1,11,26}$, as have the muscular variables $^{27-29}$. Hinkley's ${ }^{19}$ algorithm seeks to identify the moment at which these changes occur in each variable. It should be emphasized that the response of each variable, regardless of the system, breaks from linearity at some point during the test.

$\dot{\mathrm{VO}}_{2}$ values at the first turn point in HMM-HR and STPM were strongly correlated. These results are supported by other studies that have used linear ${ }^{7,8,11}$ or curvilinear ${ }^{28}$ mathematical models for fitting HR data collected during an incremental dynamic exercise test and detected a point at which the HR response lost its linearity in relation to the workload increment.

Nevertheless, the majority of mathematical modeling studies in this area have dealt with determining the second HR turn point, which is strongly correlated with the second abrupt increase in blood lactate that occurs around $4 \mathrm{mmol} / \mathrm{l}^{10-12,26}$. Although there are few studies dealing with the first HR turn point in the literature, they should be valued for their potential use in clinical practice. Such research could provide effective parameters for prescribing exercise intensity for the elderly, heart patients or other types of patients who do not need incremental exercise tests to exhaustion. As for HMM-RMS, our results showed that this method was not significantly different from the standard first turn point method expressed as workload, $\dot{\mathrm{VO}}_{2}$, and HR.

The results of the present investigation corroborate the findings of Lucía et al. ${ }^{27}$, who used a bisegmented linear method that detected the breakpoint between vastus lateralis myoelectric signal and workload increment. These authors reported that this point coincides with an increase in the oxygen ventilatory equivalent, i.e. the first turn point for ventilatory variables.

However, other studies have found conflicting results when using visual methods to identify change points in myoelectric signal response patterns. Glass et al. ${ }^{28}$ found no break point in the vastus lateralis signal for half of their volunteers during an incremental dynamic exercise test. Bearden and Moffatt ${ }^{29}$ found two break points in the sEMG data and in ventilatory and metabolic variables. The authors reported that the break points of the RMS/ workload ratio coincided with the first and second ventilatory turn points (i.e. first and second $\dot{\mathrm{VO}}_{2}$ thresholds, respectively). 
An important aspect to be discussed in the present investigation is that changes in the response patterns of the cardiorespiratory and muscular variables were interlinked and interdependent. Therefore, quantification of the first turn point can be achieved by dynamic analysis of these variables, whose disproportionate increases are relative to the cardiorespiratory adjustments necessary to supply the growing metabolic demand from increased motor unit recruitment. This increase in the recruitment of motor units is reflected by an accentuated elevation in the RMS of the sEMG, which occurs near the exercise intensity of the first ventilatory turn point.

This study has important practical implications, since quantification of the first turn point provides useful information about aerobic training by determining an important means of prescribing exercise intensity for different individuals. Therefore, considering that this study showed good agreement between the tested methods, simpler variables that are also less expensive to monitor, such as HR, can be used to determine the anaerobic threshold by applying mathematical models. Such methods can help to determine the anaerobic threshold and to give more objectivity to the prescription of physical exercise as well as reevaluation of cardiorespiratory and metabolic variables after a certain period of training.

Furthermore, it should be noted that beat-to-beat HR collection and analysis equipment is becoming increasingly accessible, making this approach a feasible tool for coaches, athletes, and gym users, as well as for rehabilitation programs in medical and physical therapy clinics.

In conclusion, the mathematical models proposed in the present investigation were effective for detecting pattern changes in $\dot{\mathrm{VCO}}_{2}, \mathrm{HR}$, and sEMG responses. The results of the present study are encouraging for those who prescribe physical exercise and evaluate functional aerobic capacity in that they allow adequate quantification of the anaerobic threshold with simpler tools for use with acquired biological signals, such as HR.

\section{- Acknowledgements}

This study was funded by CAPES (Coordenação de Aperfeiçoamento de Pessoal de Nivel Superior, Brazil) and FAPESP (Fundação de Amparo a Pesquisa do Estado de São Paulo, Brazil). The Rodrigo Lúcio Ortolan and Carlos Alberto Ribeiro Diniz for the technical assistance.

\section{References}

1. Wasserman K, Hansen JE, Sue D, Whipp BJ, Casaburi R. Principles of exercise testing and interpretation. 3rd ed. Philadelphia: Williams \& Wilkins; 1999.

2. Skinner JS, McLellan TH. The transition from aerobic to anaerobic metabolism. Res Q Exerc Sport. 1980;51:23448. http://dx.doi.org/10.1080/02701367.1980.10609285

3. Binder RK, Wonisch M, Corra U, Cohen-Solal A, Vanhees L, Saner H, et al. Methodological approach to the first and second lactate threshold in incremental cardiopulmonary exercise testing. Eur J Cardiovasc Prev Rehabil. 2008;15:726-34. PMid:19050438. http://dx.doi. org/10.1097/HJR.0b013e328304fed4

4. Beaver WL, Wasserman K, Whipp BJ. A new method for detecting anaerobic threshold by gas exchange. J Appl Physiol. 1986;60(6):2020-7. PMid:3087938.

5. Wasserman K. The anaerobic threshold measurement to evaluate exercise performance. Am Rev Respir Dis. 1984;129:S35-40. PMid:6421216.

6. Soler AM, Folledo M, Martins LEB, Lima-Filho EC, Gallo L Jr. Anaerobic threshold estimation by statistical modelling. Braz J Med Biol Res. 1989;22:795-7. PMid:2620195.

7. Crescêncio JC, Martins LE, Murta LO, Antloga CM, Kozuki RT, Santos MD, et al. Measurement of anaerobic threshold during dynamic exercise in healthy subjects: Comparison among visual analysis and mathematical models. Comput Cardiol. 2003;30:801-4.

8. Higa MN, Silva E, Neves VF, Catai AM, Gallo L Jr, Silva de Sá MF. Comparison of anaerobic threshold determined by visual and mathematical methods in healthy women. Braz J Med Biol Res. 2007;40(4):501-8. PMid:17401493. http://dx.doi.org/10.1590/S0100-879X2007000400008

9. Hopker JG, Jobson SA, Pandit JJ. Controversies in the physiological basis of the 'anaerobic threshold' and their implications for clinical cardiopulmonary exercise testing. Anaesthesia. 2011;66:111-23. PMid:21254986. http:// dx.doi.org/10.1111/j.1365-2044.2010.06604.x

10. Conconi F, Ferrari M, Ziglio PG, Droghetti P, Codeca L. Determination of the anaerobic threshold by a noninvasive field test in runners. J Appl Physiol. 1982;52:869-73. PMid:7085420.

11. Hofmann P, Bunc V, Leitner H, Pokan R, Gaisl G. Heart rate threshold related to lactate turn point and steady-state exercise on a cycle ergometer. Eur J Appl Physiol Occup Physiol. 1994;69:132-9. PMid:7805667. http://dx.doi. org/10.1007/BF00609405

12. Hofmann P, Von Duvillard SP, Seibert FJ, Pokan R, Wonisch M, Lemura LM, et al. \%HRmax target heart rate is dependent on heart rate performance curve deflection. Med Sci Sports Exerc. 2001;33(10):1726-31. PMid:11581558. http://dx.doi.org/10.1097/00005768-200110000-00017

13. Hofmann P, Wonisch M, Pokan R, Schwaberger G, Smekal G, Von Duvillard SP. Beta1-Adrenoceptor Mediated Origin of the Heart Rate Performance Curve Deflection. Med Sci Sports Exerc. 2005;37(10):1704-9. PMid:16260969. http://dx.doi.org/10.1249/01.mss.0000176308.70316.cc 
14. Jürimäe J, Von Duvillard SP, Mäestu J, Cicchella A, Purge $\mathrm{P}$, Ruosi S, et al. Aerobic-anaerobic transition intensity measured via EMG signals in athletes with different physical activity patterns. Eur J Appl Physiol Occup Physiol. 2007;101:341-6. PMid:17624542. http://dx.doi. org/10.1007/s00421-007-0509-5

15. Candotti CT, Loss JF, Melo MO, La Torre M, Pasini M, Dutra LA, et al. Comparing the lactate and EMG thresholds of recreational cyclists during incremental pedaling exercise. Can J Physiol Pharmacol. 2008;86(5):272-8. PMid:18432288. http://dx.doi.org/10.1139/Y08-020

16. Graef JL, Smith AE, Kendall KL, Walter AA, Moon JR, Lockwood CM, et al. The relationships among endurance performance measures as estimated from $\mathrm{VO}_{2 \text { PEAK }}$, ventilatory threshold, and electromyographic fatigue threshold: a relationship design. Dyn Med. 2008;7(15):1-5. http://dx.doi.org/10.1186/1476-5918-7-15

17. Karlsson J, Jacobs I. Onset of blood lactate accumulation during muscular exercise as a threshold concept. Int $\mathbf{J}$ Sports Med. 1982;3:190-201. PMid:6759424. http:// dx.doi.org/10.1055/s-2008-1026087

18. Al-Mulla MR, Sepulveda F, Colley M. A review of non-invasive techniques to detect and predict localized muscle fatigue. Sensors. 2011;11(4):3545-94. PMid:22163810 PMCid:PMC3231314. http://dx.doi. org/10.3390/s110403545

19. Hinkley DV. Inference about the intersection in two-phase regression. Biometrika. 1969;56(3):495-504. http://dx.doi. org/10.1093/biomet/56.3.495

20. Silva E, Catai AM, Trevelin LC, Guimarães JO, Silva LP Jr, Silva LMP, et al. Design of a computerized system to evaluate the cardiac function during dynamic exercise. Phys Med Biol. 1994;33:409.

21. Basmajian JV, De Luca CJ. Muscles alive: their functions revealed by electromyography. Baltimore: Williams \& Wilkins; 1985.

22. Jammes Y, Caquelard F, Badier M. Correlation between surface electromyogram, oxygen uptake and blood lactate concentration during dynamic leg exercises. Respir Physiol. 1998;112:167-74. http://dx.doi.org/10.1016/ S0034-5687(98)00023-1
23. Bland JM, Altman DG. Statistical methods for assessing agreement between two methods of clinical measurement. Lancet. 1986;1:307-10. http://dx.doi.org/10.1016/ S0140-6736(86)90837-8

24. Lamarra N. Variables, constants, and parameters: clarifying the system structure. Med Sci Sports Exerc. 1990;22:88-95. PMid:2304410. http://dx.doi. org/10.1249/00005768-199002000-00014

25. Rosic G, Pantovic S, Niciforovic J, Colovic V, Rankovic V, Obradovic Z, et al. Mathematical analysis of the heart rate performance curve during incremental exercise testing. Acta Physiol Hung. 2011;98(1):59-70. PMid:21388932. http://dx.doi.org/10.1556/APhysiol.98.2011.1.8

26. Bunc V, Hofmann P, Leitner H, Gaisl G. Verification of the heart rate threshold. Eur J Appl Physiol. 1995;70:2639. http://dx.doi.org/10.1007/BF00238574

27. Lucía A, Vaquero AF, Pérez M, Sánchez V, Gómez MA, Chicharro JL. Electromyographic response to exercise in cardiac transplant patients. Chest. 1997;111(6):1571-6. PMid:9187176. http://dx.doi. org/10.1378/chest.111.6.1571

28. Glass SC, Knowlton RG, Sanjabi PB, Sullivan JJ. Identifying the integrated electromyographic threshold using different muscles during incremental cycling exercise. J Sports Med Phys Fitness. 1998;38(1):47-52. PMid:9638032.

29. Bearden SE, Moffatt RJ. Leg electromyography and the $\mathrm{VO}_{2}$-power relationship during bycicle ergometry. Med Sci Sports Exerc. 2001;33(7):1241-5. PMid:11445775. http://dx.doi.org/10.1097/00005768-200107000-00025

\section{Correspondence}

\section{Antonio Roberto Zamunér}

Rua Argentina, 80, Vila Prudente CEP 13420-516, Piracicaba, SP, Brazil

e-mail: beto.zam@gmail.com 